\title{
Analytical, FEA, and Experimental Comparisons of Piezoelectric Energy Harvesting Using Engine Vibrations
}

\author{
Abhay Khalatkar, V. K. Gupta, and Ankit Agrawal \\ Indian Institute of Information Technology, Design and Manufacturing, Jabalpur 482005, India \\ Correspondence should be addressed to Abhay Khalatkar; abhay.iiitj@gmail.com
}

Received 28 October 2013; Revised 22 February 2014; Accepted 6 March 2014; Published 6 April 2014

Academic Editor: Dan Liu

Copyright ( 2014 Abhay Khalatkar et al. This is an open access article distributed under the Creative Commons Attribution License, which permits unrestricted use, distribution, and reproduction in any medium, provided the original work is properly cited.

\begin{abstract}
Piezoelectric elements can be used as sensors and actuators in flexible structures. In this paper, using the most basic concepts of piezoelectric micropower generators, all useful mathematical equations for getting analytical output are discussed and derived for different piezo positions on cantilever beam and then 3D finite element modeling and simulation of generalized piezoelectric laminated beam problem with proper specifications and properties are done in ANSYS12.0. Experimental analysis is also done on the very practical problem to harvest energy (to get electric energy) by applying some deflection (mechanical energy) on piezobonded aluminum beam, that is, to harvest energy (at microlevel at least) by using vibrations of 4-stroke car diesel engine with mounting of piezo cantilever beam. Here piezoelectric beam is used to measure the charge generated from the engine vibrations. The vibration amplitudes are measured with a Laser Vibrometer with considerations of maximum number of power cycles is to be covered for analysis. The vibration response data of displacement of the cantilever at free end measured from Vibrometer are considered for harmonic and analytical analyses as mean displacement amplitude of $3.98 \mathrm{~mm}$ at free end. The study further carried out for effect of different piezo positions and various engine speeds also. Then comparison is also done among obtained results from these three analyses to get validation of all derived mathematical equations.
\end{abstract}

\section{Introduction}

Over the past decade there has been an abundant increase of interest in self-powered devices in engineering applications such as MEMS, continuous structural health monitoring, environmental monitoring, and portable electronics. For such applications, to achieve their full potential, we must develop practical solutions for the power supply of the electronic devices. Energy harvesting from ambient sources, such as mechanical vibrations, is a very promising alternative. One of the most efficient ways of harvesting vibration energy is piezoelectric transduction $[1,2]$. Recently the piezoelectric materials are extensively used in electromechanical and microelectromechanical actuators and sensors. Piezoelectric materials have found widespread application as transducers that are able to change electrical energy into mechanical motion or force or vice versa [3]. Finite element analysis is extensively used for the modeling of such materials. "ANSYS" is a useful tool to simulate the structure of piezoelectric devices successfully and accurately [4]. Saadon and Sidek [5] propose a comparative study on the obtained results of the energy delivered from the ambient vibration-based MEMS energy harvester using the ANSYS and COVENTORWARE approaches. The improvement reflected in the experimental results for vibration-based MEMS piezoelectric energy harvesters indicates excellent application scope in power MEMS and green energy. Patel et al. [6] propose a versatile model for optimizing the performance of a rectangular cantilever beam piezoelectric energy harvester used to convert ambient vibrations into electrical energy. The developed model accounts for geometric changes to the natural frequencies, mode shapes, and damping in the structure. Zhou et al. [7] proposed and investigated a novel piezoelectric energy harvester with a multimode dynamic magnifier, which is capable of significantly increasing the bandwidth and the energy harvested from the ambient vibration. The design comprises a multimode intermediate beam with a tip mass, called a dynamic magnifier. Wen Xu et al. [8] present experiments and 
models of a piezoelectric cantilever generator with a rightangle structure. Analysis shows that the extended part provides a large torque to the main beam, which can dramatically smoothen the strain distribution of the main beam; their model based on the Rayleigh-Ritz method is established to demonstrate the principle of the strain-smoothing effect. AlAshtari et al. [9] focus on the limitations of the frequency tuning techniques and propose a model for frequency tuning of piezoelectric energy harvesters by magnetic force which describes the design and testing of a vibration energy harvester with tunable resonance frequency, wherein the tuning is accomplished by changing the attraction force between two permanent magnets. Zhu et al. [10] also present a design study on the geometric parameters of a cantileverbased piezoelectric energy harvesting devices (EHD), which harvest energy from motion (vibration), for the purpose of scavenging more energy from ambient vibration energy sources. Lu et al. [11] propose some analytical solutions and experimental comparisons of a piezoelectric cantilever when the beam exits at free end.

In this paper, we proposed a case study and a model to harvest energy from the engine vibrations. As it is well known that engine vibrations are undesired phenomenon, so we propose a piezoelectric energy harvester to harvest energy from engine vibrations. Piezoelectric material is used to convert mechanical vibrations to electrical energy. Related characteristic equations are solved analytically and results are compared using finite element and experimentation. Experiments are conducted on four-stroke diesel engines with the piezo-mounted cantilever beam. For this energy harvesting problem, PZT-5A4E is used as a piezoelectric material. The cantilever beam consists of piezoelectric bimorph mounted on one side of an aluminum beam. Piezoelectric bimorph uses in this experiment are with $0.13 \mathrm{~mm}$ thick substrate layer which covered by $0.19 \mathrm{~mm}$ piezo layers both sides. The sizes (length $\times$ width $\times$ thickness) for bimorph and beam are about $64 \times 32 \times 0.19$. The cantilever beam sizes on which piezo bimorph mounted are $350 \times 32 \times 0.8$ (in mm). FEA solution is obtained by ANSYS. Modal and harmonic analysis are done to find out the first natural frequency, which is obtained as $14.16 \mathrm{~Hz}$ at a deflection of $3.98 \mathrm{~mm}$ at the free end of a cantilever beam. Output power is obtained as $194.7 \mu \mathrm{W}$ by FEA solution. Analytical solution for the same is obtained in which power was calculated as $200.8 \mu \mathrm{W}$. Experiments are also conducted to verify the model by mounting piezo patch mounted over an aluminum cantilever beam at different piezo positions and attempt is made to find out the best optimal position. In experimental analysis power is generated by measuring voltage and current by piezoelectric patch which is found to be $181.7 \mu \mathrm{W}$ in a particular case study when piezo mounted at $282 \mathrm{~mm}$ from the fix end of cantilever beam. The vibration amplitudes are measured with the help of a Laser Vibrometer. During the initial experiment, speed of the engine is kept near to $850 \mathrm{rpm}$ according to match the natural frequency which was found by FEA solution. FEA and experimental analysis are carried out at seven different positions of piezo patch over cantilever beam to find out optimal piezo position and then the analysis further expanded to find out the charge generated at different engine speeds. Experimental results are compared with analytical result, which is found to be a good match.

\section{Coupling Equations for Piezoelectric Generator}

For a one-degree of freedom system generator, such as a piezoelectric laminated beam vibrating under single bending modal, the mechanical-electrical coupling equations can be expressed as follows:

$$
\begin{aligned}
m \ddot{\theta}+c \dot{\theta}+k \theta-K_{\mathrm{me}} \cdot \vartheta & =f(t), \\
q-K_{\mathrm{me}} \cdot \theta-C_{p} \cdot \vartheta & =0,
\end{aligned}
$$

where $m, c$, and $k$ are modal mechanical mass, modal mechanical damping coefficient, and modal mechanical stiffness, respectively. $K_{\mathrm{me}}$ is the modal piezoelectric coupling stiffness, $f(t)$ is the modal external mechanical force, $\theta$ is the modal displacement, $\vartheta$ is the difference in electric potential between the electrodes, $q$ is the electric charge on the electrodes, and $C_{p}$ is the piezoelectric material inherent capacitance. The coupling stiffness and the inherent capacitance are functions of the mechanical design parameters as well as the piezoelectric material properties.

In general, a larger coupling coefficient gives higher conversion efficiency. Under certain external excitations, the vibration amplitude of the generated element will be affected by the external electrical load, which is driven by the electrical power induced from the piezoelectric generator. The general equation for output voltage and the charge can be expressed as follows:

$$
F(\vartheta)+G(q)=0
$$

where $F(\vartheta)$ and $G(q)$ are linear differential operators with respect to time $t$. The coupling dynamical equations (1) and (2) describe the relationship between the mechanical variable $\theta(t)$ and electrical variable $q(t)$. The shunting circuit equation (3) gives the condition of electric load. When the external impedance is a pure resistance $R$ and if the internal resistance for whole electric closed loop is neglected, then (3) can be expressed as

$$
R \dot{q}+\vartheta=0 .
$$

Substituting (4) into (2), the following coupling equations can be derived:

$$
\begin{gathered}
m \ddot{\theta}+c \dot{\theta}+\left(k+\frac{K_{\mathrm{me}}^{2}}{C_{p}}\right) \cdot \theta-\left(\frac{K_{\mathrm{me}}}{C_{p}}\right) \cdot q=f(t), \\
R \dot{q}+\frac{q}{C_{P}}-\left(\frac{K_{\mathrm{me}}}{C_{p}}\right) \cdot \theta=0 .
\end{gathered}
$$

\section{Analytical Formulation of Piezoelectric Power Generators}

It is easy to achieve a certain amount of stress with the "31mode" generators by bonding the piezoelectric element to a 
TABLE 1: Beam geometry and material properties of aluminum and piezo PZT-5A.

\begin{tabular}{lccc}
\hline Properties & Aluminum & PZT-5A & Substrate \\
\hline Length & $L_{b}=350 \mathrm{~mm}$ & $L=64 \mathrm{~mm}$ & $L=64 \mathrm{~mm}$ \\
Width & $b=32 \mathrm{~mm}$ & $32 \mathrm{~mm}$ & $32 \mathrm{~mm}$ \\
Thickness & $h=0.8 \mathrm{~mm}$ & $\Delta=0.19 \mathrm{~mm}$ & $\Delta=0.13 \mathrm{~mm}$ \\
Density & $2700 \mathrm{~kg} / \mathrm{m}^{3}$ & $7500 \mathrm{~kg} / \mathrm{m}^{3}$ & $8600 \mathrm{~kg} / \mathrm{m}^{3}$ \\
Relative permittivity & & $1700 * 8.85 e-12 \mathrm{Fm}^{-1}$ & $9.7 e 10 \mathrm{~N} / \mathrm{m}^{2}$ \\
Modulus of elasticity & $2.1 * e 11 \mathrm{~N} / \mathrm{m}^{2}$ & $5 e 10 \mathrm{~N} / \mathrm{m}^{2}$ & 0.31 \\
Poisson's ratio & 0.33 & 0.31 & \\
\hline
\end{tabular}

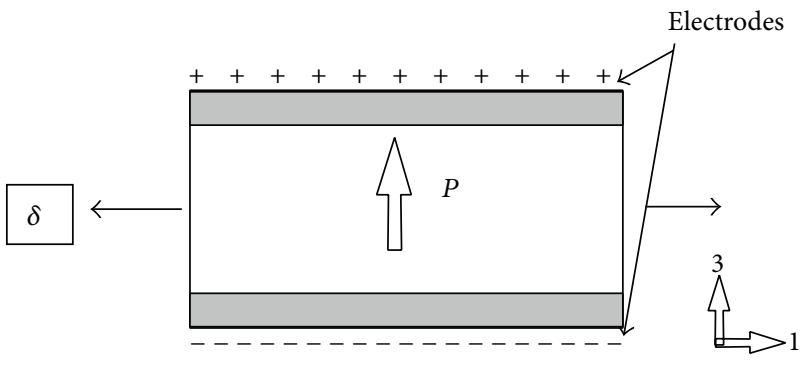

FIGURE 1: 31 direction: force at 1-direction and electrode on 3surface.

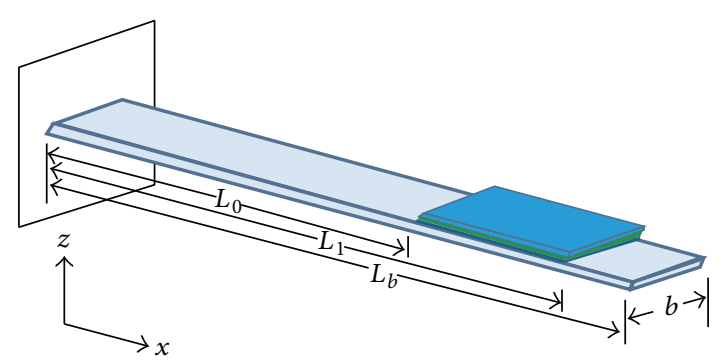

Figure 2: Prototype of the piezoelectric power generator. $L_{0}=$ Length of beam from which Piezo starts, $L_{1}=$ Length of beam at which piezo ends, $L_{b}=$ Total length of the beam and $b=$ Width of beam.

substructure undergoing bending. In comparison with "33mode" generators, this is more suitable for MEMS applications [12]. 31 direction poling is shown in Figure 1.

A typical 31-mode power generator is a beam type piezoelectric power generator, in which a piezoelectric layer is bonded to a host element. When the host element is vibrating under the external excitation, a corresponding deformation is induced in the piezoelectric layer. A prototype of a piezoelectric laminated beam generator is shown in Figure 2. In order to simplify the analysis, the generator is regarded as a cantilever beam with uniform thickness. Based on the elastic theory of a beam, the displacement in the $x$ direction for a point within the beam can be expressed as

$$
u_{x}=u_{0}(x, t)-z \frac{d w(x, t)}{d x},
$$

where $u_{x}$ is the displacement in $x$-direction, $u_{0}$ is the axial displacement, which is neglected in this case, $w$ is the transverse displacement of the beam, and $z$ is the distance from the neutral plane. The strain along the $x$-direction is expressed as

$$
\epsilon_{x}=\frac{d u_{x}}{d x}=-z \frac{d^{2} w}{d x^{2}}
$$

Finally the estimated power equation is as follows:

$$
\bar{P}=\frac{\omega^{2} b^{2} h^{2} e_{31}^{2} \bar{A}^{2} R}{4\left(1+b L \varepsilon_{33} \omega R / \Delta\right)^{2}} .
$$

This derived equation is used to calculate the analytical power for the piezoelectric power generators.

\section{Analyses of Energy Harvesting Using Engine Vibrations.}

FEA, analytical, and experimental analyses with comparison are discussed for energy harvesting using 4-stroke car diesel engine vibrations. Here, the particular case in which the piezoelectric patch (PZT-5A) fitted on beam fixed at $282 \mathrm{~mm}$ from fixed end of the cantilever is considered. Experimental work is done with a piezoelectric cantilever aluminum beam mounting over the engine. Material properties and geometrical details of aluminum and piezoelectric patch (PZT-5A) are given in Table 1.

The following details are also used for getting analytical and FEA solution.

Resistance $[R]=40 \mathrm{k} \Omega$.

Vibration amplitude at free end of cantilever $[A]=$ $3.98 e-3 \mathrm{~m}$.

The distance of piezo from fix end $\left[L_{0}\right]=282 \mathrm{~mm}$.

The end point distance of piezo from fix end $\left[L_{1}\right]=$ $346 \mathrm{~mm}$.

4.1. FEA Modeling. For energy harvesting by aluminum cantilever beam mounted on car diesel engine, the FEA model created for the same using all the necessary properties and specifications shown in Figure 3.

After creating the model in ANSYS12.0, the first modal frequency in modal analysis is found to be $14.16 \mathrm{~Hz}$. The deflection of $3.98 \mathrm{~mm}$ (experimentally obtained, Figure 5) applied at the free end of the beam for FEA harmonic analysis 


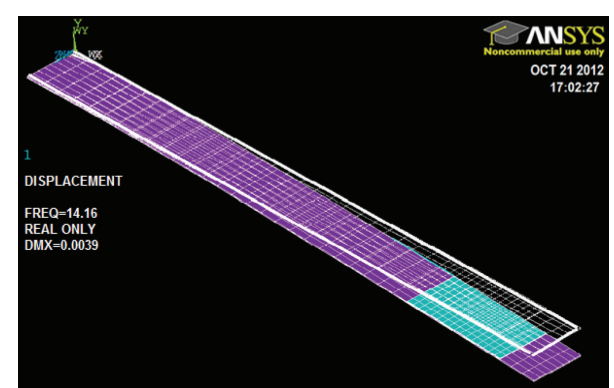

FIgURE 3: FEA model of cantilever beam built in ANSYS 12.1.

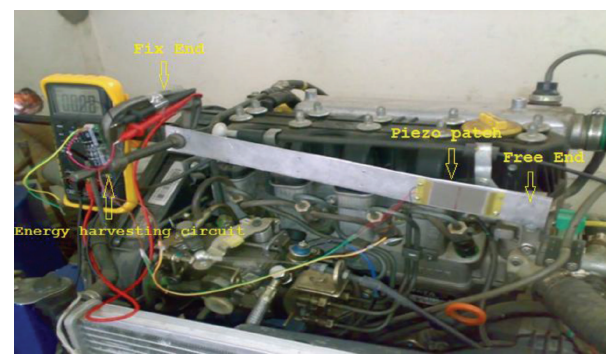

FIGURE 4: Experimental setup with aluminum cantilever beam with piezo mounted at $282 \mathrm{~mm}$ from fix end.

and displacement amplitude data for a period of 6.5 seconds is considered for transient analysis. Then the harmonic and transient analyses are carried out to find out the voltage and current on the piezoelectric surface after applying the piezoelectric FEA circuit. The FEA voltage and current on the piezoelectric surface are obtained by drawing a path on upper surface considering maximum nodes in a straight line. Thus voltage is measured to be 2.82 volts and the current is $0.069 \mathrm{~mA}$. So the FEA power calculated $[P]=$ volt $*$ current $=194.7 \mu$ watt.

4.2. Experimental Analysis. For the purpose of harvesting energy by using the vibrations of running the engine, arrangement of piezoelectric (PZT-5A), Al beam and piezoelectric circuit properly was done and then mounted this cantilever beam (with clamping) on the engine to get the voltage and current output using engine vibrations with the help of Multimeter, Laser Vibrometer, stop watch, and piezoelectric circuit. There are some figures shown below which represent the experimental setup and work analysis. Figure 4 shows the experimental engine setup of cantilever aluminum beam with piezo fitted at $282 \mathrm{~mm}$ from fix end on it, piezoelectric circuit, and Multimeter. This figure also describes the fix and vibrating ends of the beam mounted over the engine. One end of the beam is fixed to frame structure which is rigidly connected to the foundation of the engine. And the other end of the beam is freely suspended over the most vibrating part near the block head of the engine in order to transfer vibrations from the engine to harvest energy from engine vibrations.

The charge generated in terms of voltage is collected using energy harvesting kit (Piezo system Inc., USA) and

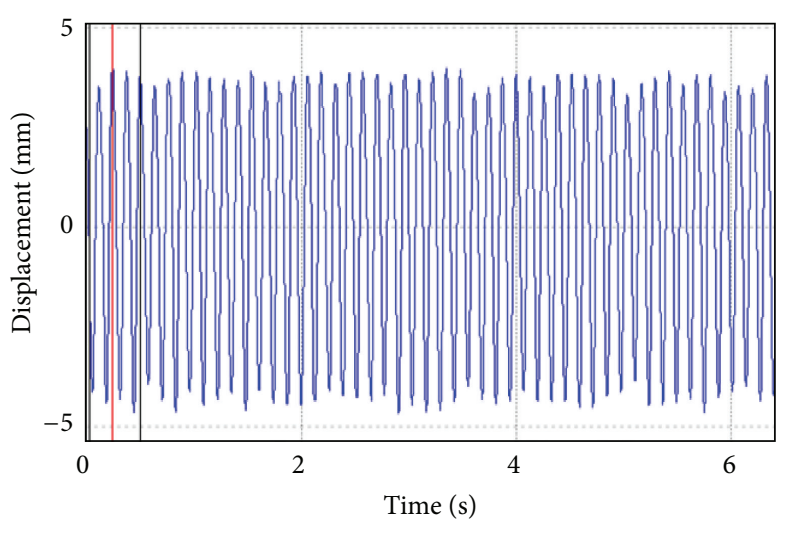

FIGURE 5: Experimental maximum vibration amplitude response of displacement $3.98 \mathrm{~mm}$ for 6.5 seconds at free end by Laser Vibrometer at $14.16 \mathrm{~Hz}$. $(850 \mathrm{rpm})$.

output is measured in Multimeter approximately at $850 \mathrm{rpm}$ engine speed. This is the crank speed of the engine. As the vibrations induced are the resultant output at this particular engine speed so in our experimentations we directly correlate the measured vibrations at particular engine speed. The energy harvesting circuit containing resistor and capacitor is connected to piezo patch. The extreme left fix end of the beam is clamped on this frame to fulfill the condition $U x=$ $U y=U z=0$ (all degrees of freedom are zero). As the engine starts, all the vibrations are transferred to the free end of the beam and the beam vibrates with the amplitude equal to the amplitude of engine vibrations. Vibration amplitude in terms of displacement in the $z$-direction is measured by Laser Vibrometer with respect to particular time intervals. These displacements can be measured in different time intervals. As the engine is in running condition the vibrations of the engine transfer to the right free end of beam on which piezo is attached and charge generated is noted down as per time scale. For a simulation of the same in ANSYS, the vibration data measured using Vibrometer is imported in a transient solution of ANSYS as time history. A sample result of vibration response to the free end of beam at $\sim 850 \mathrm{RPM}$ is shown in Figure 5.

The natural frequency of the engine measured in a FFT form (Figure 6) which shows at $14.16 \mathrm{~Hz}$ (first natural frequency) so here we consider $850 \mathrm{rpm}$ speed our for case study to harvest maximum energy at this resonance level of engine.

The experimental voltage and current are observed as 2.71 volts and $0.067 \mathrm{~mA}$. So the experimental power obtained at the speed of $\sim 850 \mathrm{rpm}$ is $181.57 \mu \mathrm{W}$.

The energy harvesting circuit containing resistor and capacitor was connected to piezo patch. The left extreme end of beam is fixed to the frame structure which is fitted in concrete foundation, which is not connected to engine body. Here the charge generated is measured up to maximum time scale of 12 minutes, keeping the engine speed constant at $850 \mathrm{rpm}$. To optimize piezo position on beam, piezo moves seven different positions across the length over beam. The seven different positions were $5 \mathrm{~mm}, 47 \mathrm{~mm}, 95 \mathrm{~mm}$, 


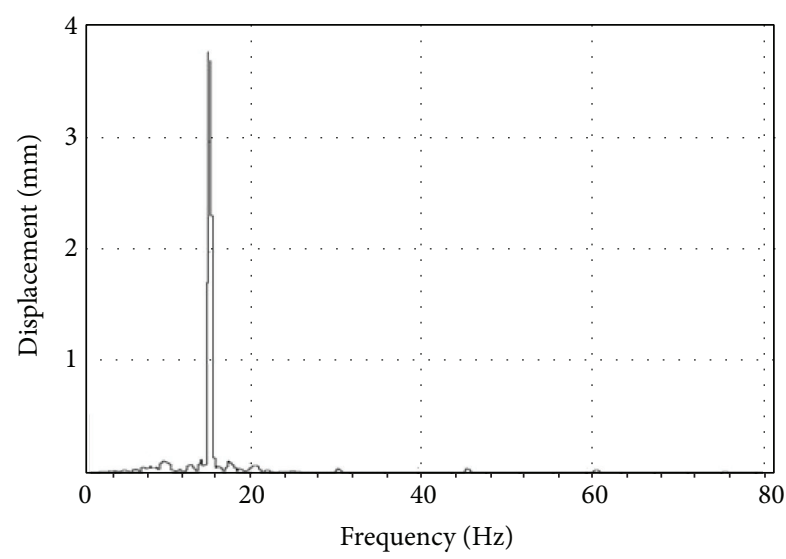

FIgURE 6: FFT response at $850 \mathrm{rpm}$ engine speed.

$141 \mathrm{~mm}, 189 \mathrm{~mm}, 236 \mathrm{~mm}$, and $282 \mathrm{~mm}$ from fix clamp end of beam and voltage generated was measured for these different locations.

\section{Results and Discussions}

\subsection{Case Study}

5.1.1. General Comparison of FEA and Experimental Results (with Speed and Different Positions). Here simulation of piezoelectric beam is done by applying the load file to a particular model by transient analysis. Piezo patch attached moves to seven different locations along the length of beam moving it from fix end of beam to the vibrating end of beam. Figure 7 shows piezo position along the beam versus voltage generated by FEA and experimental results in a combined way where maximum voltage is found to be 4.95 and 4.1 volts, respectively, when piezo is at $5 \mathrm{~mm}$ from fix end of beam.

When piezo position moves from extreme near to fix end $(5 \mathrm{~mm})$ to extreme longest from fix end $(283 \mathrm{~mm})$ the charge generated in turn of voltage is found to be less, as shown in Figure 9. Charge generated was found out to be 2.34 volt by FEA solution and 1.85 volt experimentally which is the least value among all seven different positions of piezo over the beam. This is because of the fact that strain induced more near fix end of beam when free end of cantilever beam deflects by means of engine vibrations and charge generation is directly proportional to strain induced in piezo layers. The charge generated in turns of voltage was measured as $4.95 \mathrm{v}, 4.8 \mathrm{v}$, $4.36 \mathrm{v}, 4.1 \mathrm{v}, 3.1 \mathrm{v}, 2.8 \mathrm{v}$, and $2.4 \mathrm{v}$ at $5 \mathrm{~mm}, 46 \mathrm{~mm}, 94 \mathrm{~mm}$, $140 \mathrm{~mm}, 188 \mathrm{~mm}, 235 \mathrm{~mm}$, and $282 \mathrm{~mm}$ piezo positions from fix end of beam.

5.2. Measurement of Vibration Response and Analysis of Voltage Generated at Various Speeds. In previous discussion, effect of actuator position on cantilever beam has been discussed. The analysis is done by moving actuator at seven different positions on beam in which it found that maximum voltage generated is found to be at, when piezo actuator is located at extreme position towards the fix end of beam, $5 \mathrm{~mm}$ from fix end of beam. Considering this actuator position

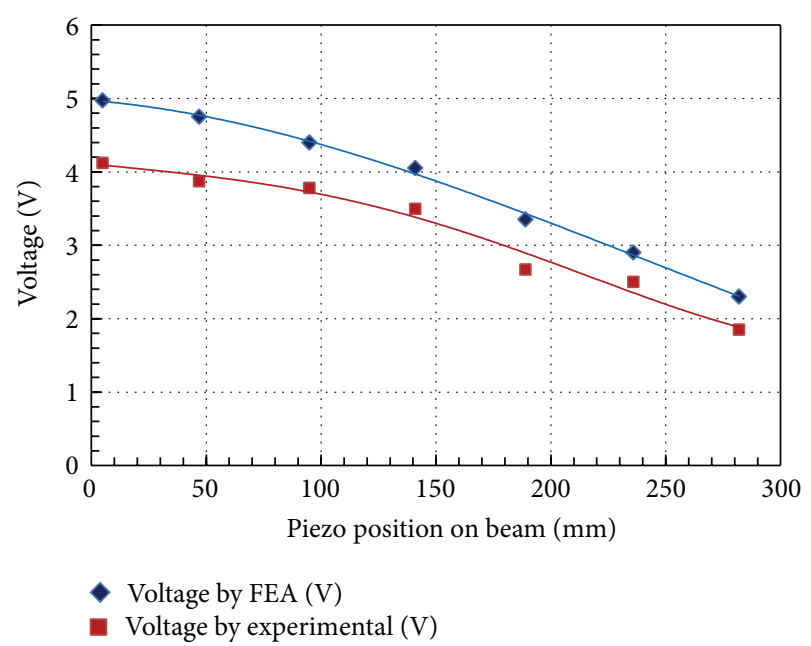

Figure 7: FEA and experimental results comparison for different piezo positions.

as maximum charge generation further study is carried out for various speeds (Figure 5) of engine from $750 \mathrm{rpm}$ to $2400 \mathrm{rpm}$.

This analysis is carried out at seventeen different speeds (rpm) of engine which are 750, 850, 950, 1075, 1155, 1250, $1350,1470,1650,1750,1840,1930,2050,2150,2250,2350$, and $2400 \mathrm{rpm}$. Vibration amplitude response in turns of transverse displacement was captured by Laser Vibrometer for 120 seconds by varying engine speed from 750 to $2400 \mathrm{rpm}$; vibration amplitude graph in real mode is shown in Figure 5. During the measurement it was found that deflection occurs maximum near to initial speed of engine, that is, at $850 \mathrm{rpm}$. Then vibration amplitude was measured less as the speed goes on increasing up to $1800 \mathrm{rpm}$ and it was measured least $0.35 \mathrm{~mm}$ at speed of 1800 to $2000 \mathrm{rpm}$. As the speed of engine increases beyond $2000 \mathrm{rpm}$ up to $2400 \mathrm{rpm}$, vibration amplitudes were measured in an increasing order which is shown in Figure 8.

After measuring vibration amplitude signature in a continuous form from 750 to $2400 \mathrm{rpm}$, charge generated in turn of voltage at particular speed individually was carried out. In this section engine speed kept constant for a particular time period and voltage generated by piezoelectric patch over the beam that was noted down with $5 \mathrm{~mm}$ distance from fix end were measured. Experimentation was carried out for 17 different speeds which mentioned as earlier. Time period for this measurement was 12 minutes. During measurement it was found that charge generated goes on increasing up to 10 minutes; after this the curve becomes constant, so data was recorded up to 12 minutes time span for every individual speed test shown in Figure 9. Charge generated measures maximum 4.1 volts at $850 \mathrm{rpm}$ and measures least 1.7 volts at 1900 and $2000 \mathrm{rpm}$.

After noting down voltage values, the same experimentation was carried out for current for estimation of power as we know that power is $P=V I$. 


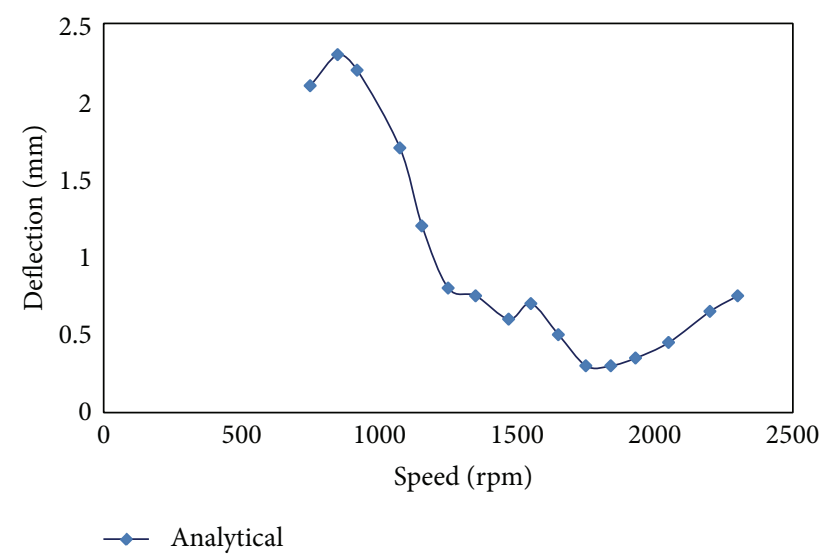

FIgURE 8: Amplitude of deflection of beam free end at various speeds.

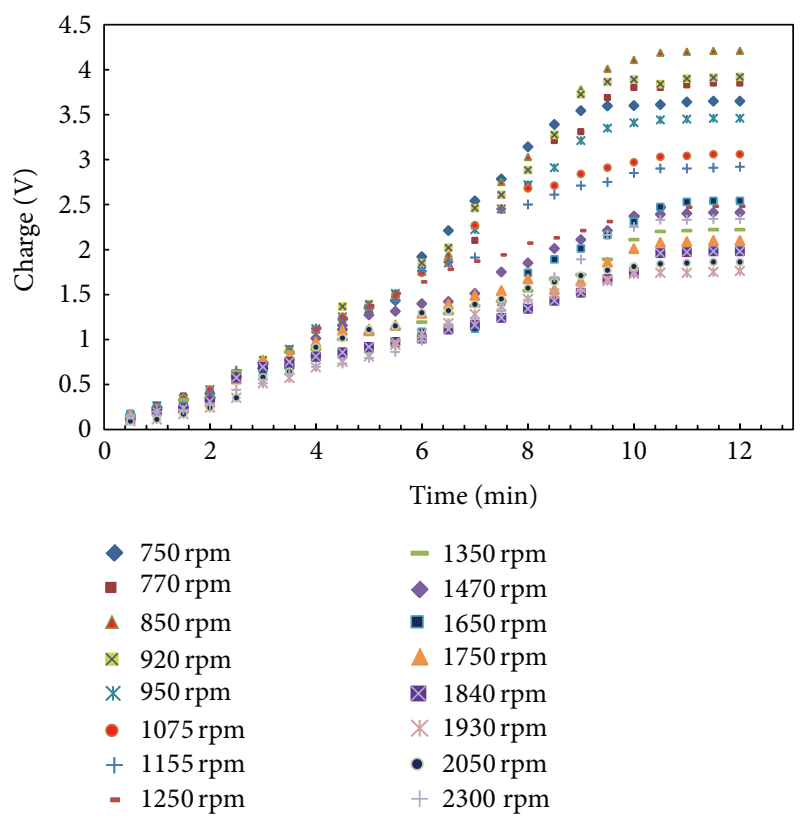

FIGURE 9: Voltage generation at various engine speeds by the end of 12 minutes.

5.3. Validation with Analytical Solution for Case Study When Piezo Was Placed at $282 \mathrm{~mm}$ from Fix End. For the different parameters of this piezoelectric power generator (cantilever beam mounted on the engine), all analytical values are obtained with the help of all previously derived mathematical formulations. The power of $200.8 \mu \mathrm{W}$ at the natural frequency of $14.16 \mathrm{~Hz}$ is obtained by using the power formula and putting all available data of beam and piezoelectric material in proper place, like

$$
\bar{P}=\frac{\omega^{2} b^{2} h^{2} e_{31}^{2} \bar{A}^{2} R}{4\left(1+b L \varepsilon_{33} \omega R / \Delta\right)^{2}},
$$

where $\omega($ system frequency) $=2 * 3.14 * 14.16=88.92 \mathrm{rad} / \mathrm{s}$; $b$ (width of aluminum beam) $=32 \mathrm{~mm} ; h$ (thickness of the beam $)=0.8 \mathrm{~mm} ; e_{31}($ piezoelectric constant $)=26.32 \mathrm{Cm}^{-2}$
TABLE 2: Comparison of the analysis results for the energy harvesting.

\begin{tabular}{lccc}
\hline Analysis & Volt $(\mathrm{V})$ & Current $(\mathrm{mA})$ & Power $(\mu \mathrm{W})$ \\
\hline FEA & 2.82 & 0.069 & 194.6 \\
Experimental & 2.71 & 0.067 & 181.57 \\
Analytical & 2.83 & 0.0709 & 200.6 \\
\hline
\end{tabular}

(referred from piezo.com); $R$ (resistance) $=40,000$ ohms; $L$ (length of piezo layer) $=64 \mathrm{~mm}$; dielectric constant of piezo $=$ $1700 * 8.85 e-12 \mathrm{Fm}^{-1}$; thickness of piezo layer $=0.19 \mathrm{~mm} ; \bar{A}$ is calculated by using $\left(W^{\prime}\left(L_{0}\right)-W^{\prime}\left(L_{1}\right)=\bar{A}\right.$, where $L_{0}$ and $L_{1}$ are $282 \mathrm{~mm}$ and $346 \mathrm{~mm}$, respectively. And $W^{\prime}(x)$ can be obtained by the first derivative with respect to $x$ of equation 18), where " $\beta$ " depends on the beam density, young's modulus, and moment of inertial area:

$$
\beta=6.6 \quad \text { (using calculation). }
$$

For the value of constant $C_{1}$, using the property of cantilever beam under vibration leads to the following.

$$
\begin{aligned}
& W(x) \mid x=L_{b}=A=3.98 e-3 \mathrm{~m} \text {, so using this } \\
& C_{1}=-2.10 e-3 . \\
& \text { Now, } W^{\prime}\left(L_{0}=282 e-3 \mathrm{~m}\right)=-5.22 e-3 . \\
& \text { And } W^{\prime}\left(L_{1}=346 e-3 \mathrm{~m}\right)=-1.39 e-3 . \\
& \text { So } \bar{A}=W^{\prime}\left(L_{0}\right)-W^{\prime}\left(L_{1}\right)=-3.83 e-3 .
\end{aligned}
$$

Hence the power is calculated by putting all data in formula as $200.8 e-6$ watts.

In order to compare the analysis results for the energy harvesting using engine vibrations, the results are summarized for a case study when piezo position is $283 \mathrm{~mm}$ from fix end of beam, as shown in Table 2 .

Figure 10 shows a clear comparison between two piezo positions: one at $5 \mathrm{~mm}$ and the other at $283 \mathrm{~mm}$. When the piezo was placed at $5 \mathrm{~mm}$ from the fix end of cantilever beam, maximum power generated was found to be $485 \mu \mathrm{W}$ at $850 \mathrm{rpm}$ which shows a decreasing trend as the speed goes on increasing; it was found to be the least value $88 \mu \mathrm{W}$ at the speed of $1900 \mathrm{rpm}$ as the vibration amplitude measured in real mode was least $0.55 \mathrm{~mm}$ at this speed.

Figure 11 shows analytical and experimental comparison of charge generated in microwatts of piezoelectric energy harvester when piezo was placed at $5 \mathrm{~mm}$ from the fix end of beam when the speed of engine varies from 750 to $2400 \mathrm{rpm}$. Maximum power generated at $850 \mathrm{rpm}$ speed was measured $485 \mu \mathrm{W}$ by analytical solution and $440 \mu \mathrm{W}$ experimentally.

It is observed that finite element solution and analytical solution are in close match (2.7\% difference). Experimental and analytical solutions are also in close match (9.5\% difference). The reason for any difference between analytical and experimental results is that the vibrations of the engine do not completely transfer to cantilever beam free end. Transmission losses occur between the engine and cantilever beam. 


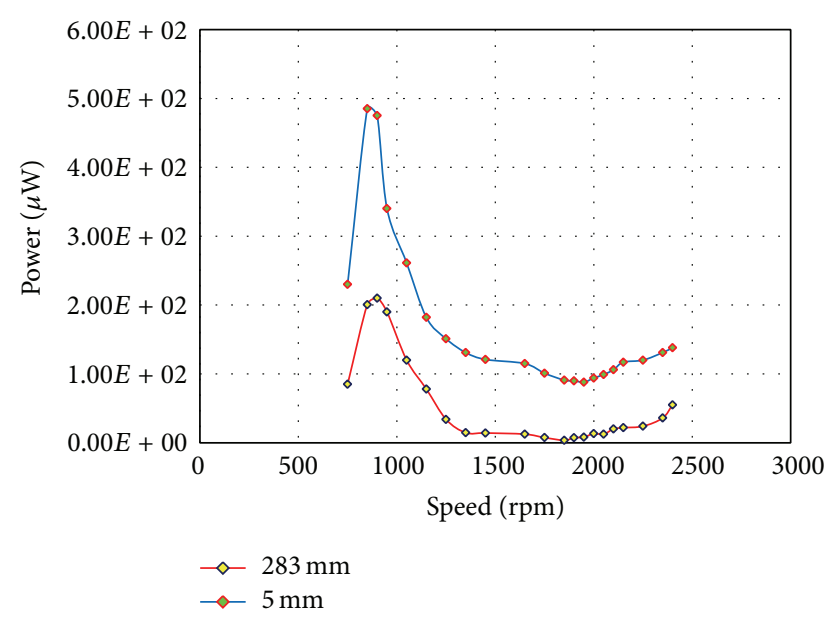

Figure 10: Comparison of analytical power generation of piezo position over cantilever beam at $5 \mathrm{~mm}$ and $283 \mathrm{~mm}$.

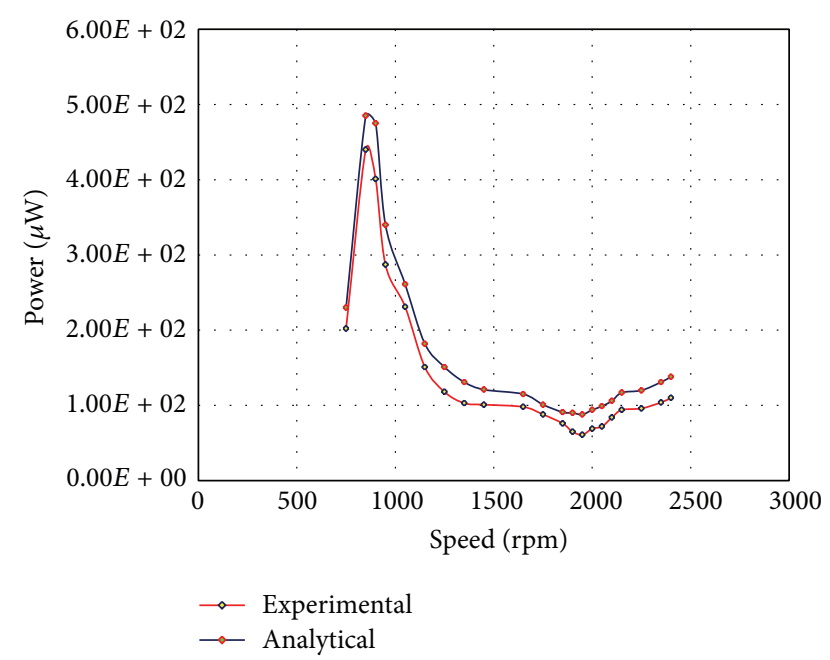

FIgURE 11: Analytical and experimental comparison when piezo position is at $5 \mathrm{~mm}$ from fix end of cantilever beam.

\section{Conclusions}

Here the results and analyses of vibration energy harvesting by engine vibrations from 4-stroke diesel car engine are presented. For the comparison of all the three analyses FEA, analytical, and experimental, we considered a special case study in which piezo is laminated at a distance of $282 \mathrm{~mm}$ from fix end. The comparison is done on the first natural frequency of $14.16 \mathrm{~Hz}$ and deflection at free end of $3.98 \mathrm{~mm}$. The output power results for this case study in FEA, experimental, and analytical analyses are $194.6 \mu \mathrm{W}$, $181.57 \mu \mathrm{W}$, and $200.6 \mu \mathrm{W}$, respectively, which are very near to each other. A case study further expanded for different piezo positions over cantilever beam to find out optimal position of piezo along the length in which it found maximum charge generation when piezo was placed very near to fix end, that is, at $5 \mathrm{~mm}$ from fix end of beam, which satisfies the phenomenon of maximum strain induced near the fix end of cantilever beam. During the further study when the piezo is placed at some fixed position ( $5 \mathrm{~mm}$ from fix end) and the speed varies from 750 to $2400 \mathrm{rpm}$, the maximum charge generation is measured at $850 \mathrm{rpm}, 485 \mu \mathrm{W}$ by analytical solution and $440 \mu \mathrm{W}$ experimentally, which concludes that this close match obtained resulting in all two analyses declares the proper validation of all mathematical derived equations with FEA and experimental work. This energy harvested by means of piezoelectric harvester would certainly help to run electronics sensors in the car or can be used as a regenerative power supply to battery.

\section{Conflict of Interests}

The authors declare that there is no conflict of interests regarding the publication of this paper.

\section{References}

[1] H. A. Sodano, D. J. Inman, and G. Park, "A review of power harvesting from vibration using piezoelectric materials," Shock and Vibration Digest, vol. 36, no. 3, pp. 197-205, 2004.

[2] S. Roundy, E. S. Leland, J. Baker et al., "Improving power output for vibration-based energy scavengers," IEEE Pervasive Computing, vol. 4, no. 1, pp. 28-36, 2005.

[3] M. Y. Yasin, N. Ahmad, and M. N. Alam, "Finite element analysis of actively controlled smart plate with patched actuators and sensors," Latin American Journal of Solids and Structures, vol. 7, no. 3, pp. 227-247, 2010.

[4] K. Ramesh Kumar and S. Narayanan, "Active vibration control of beams with optimal placement of piezoelectric sensor/actuator pairs," Smart Materials and Structures, vol. 17, no. 5, Article ID 055008, pp. 15-20, 2008.

[5] S. Saadon and O. Sidek, "Transient analysis of ambient vibration-based micro-electro-mechanical systems (MEMS) piezoelectric energy harvester using ANSYS and COVENTORWARE approaches," in Proceedings of the IEEE Conference on Computer Applications and Industrial Electronics (ICCAIE '11), pp. 41-44, IEEE, December 2011.

[6] R. Patel, S. McWilliam, and A. A. Popov, "A geometric parameter study of piezoelectric coverage on a rectangular cantilever energy harvester," Smart Materials and Structures, vol. 20, no. 8, Article ID 085004, 2011.

[7] W. Zhou, G. R. Penamalli, and L. Zuo, "An efficient vibration energy harvester with a multi-mode dynamic magnifier," Smart Materials and Structures, vol. 21, no. 1, Article ID 015014, 2012.

[8] J. Wen Xu, Y. Bing Liu, W. Shao, and Z. Feng, "Optimization of a right-angle piezoelectric cantilever using auxiliary beams with different stiffness levels for vibration energy harvesting," Smart Material Structure, vol. 21, Article ID 065017, pp. 13-19, 2011.

[9] W. Al-Ashtari, M. Hunstig, T. Hemsel, and W. Sextro, "Frequency tuning of piezoelectric energy harvesters by magnetic force," Smart Materials and Structures, vol. 21, no. 3, Article ID 035019, 2012.

[10] M. Zhu, E. Worthington, and A. Tiwari, "Design study of piezoelectric energy-harvesting devices for generation of higher electrical power using a coupled piezoelectric-circuit finite element method," IEEE Transactions on Ultrasonic's, Ferroelectrics, and Frequency Control, vol. 57, pp. 46-51, 2010. 
[11] F. Lu, H. P. Lee, and S. P. Lim, "Modeling and analysis of micro piezoelectric power generators for micro-electromechanicalsystems applications," Smart Materials and Structures, vol. 13, no. 1, pp. 57-63, 2004.

[12] J. Ajitsaria, S. Y. Choe, D. Shen, and D. J. Kim, "Modeling and analysis of a bimorph piezoelectric cantilever beam for voltage generation," Smart Materials and Structures, vol. 16, no. 2, article 024, pp. 447-454, 2007. 

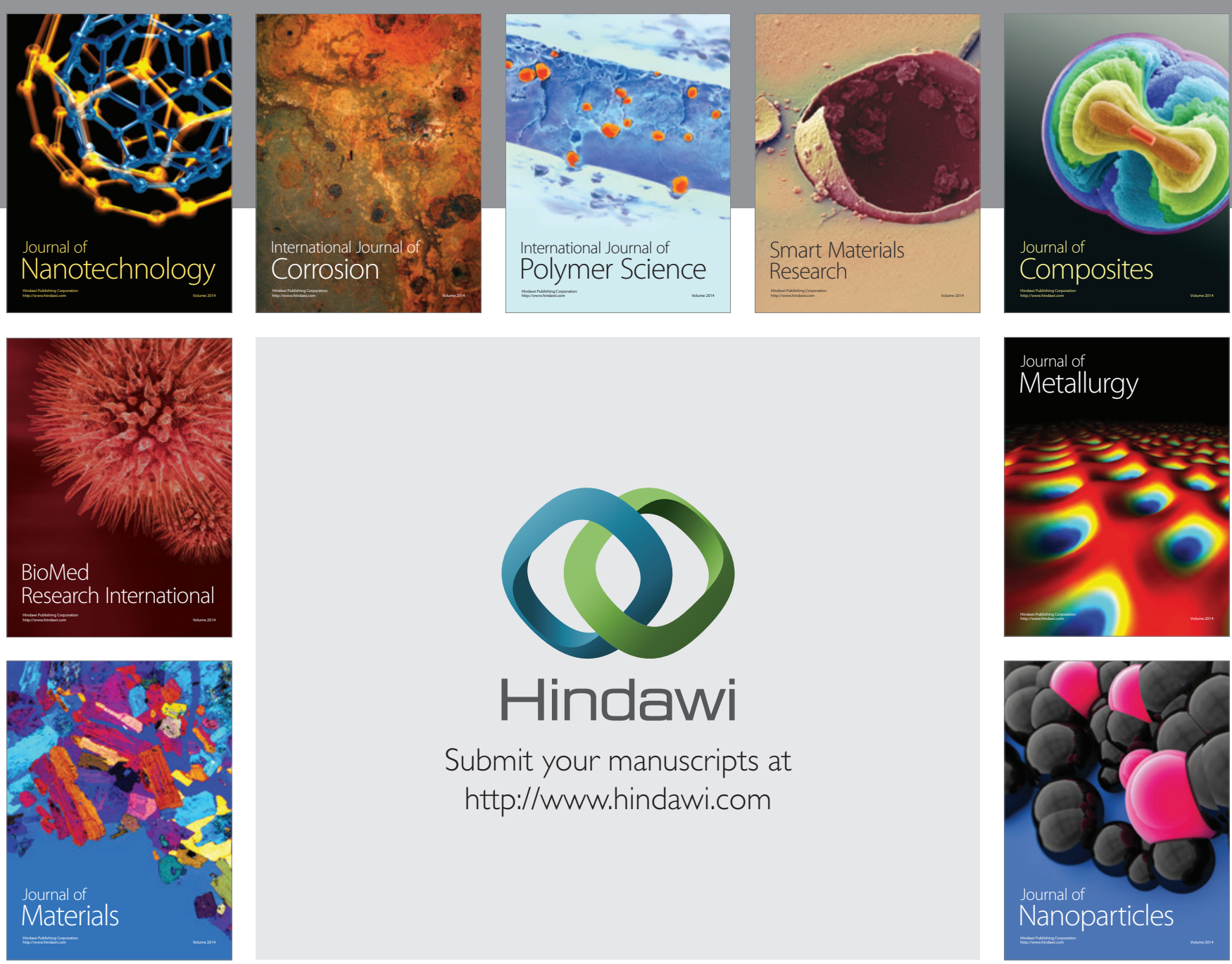

Submit your manuscripts at http://www.hindawi.com
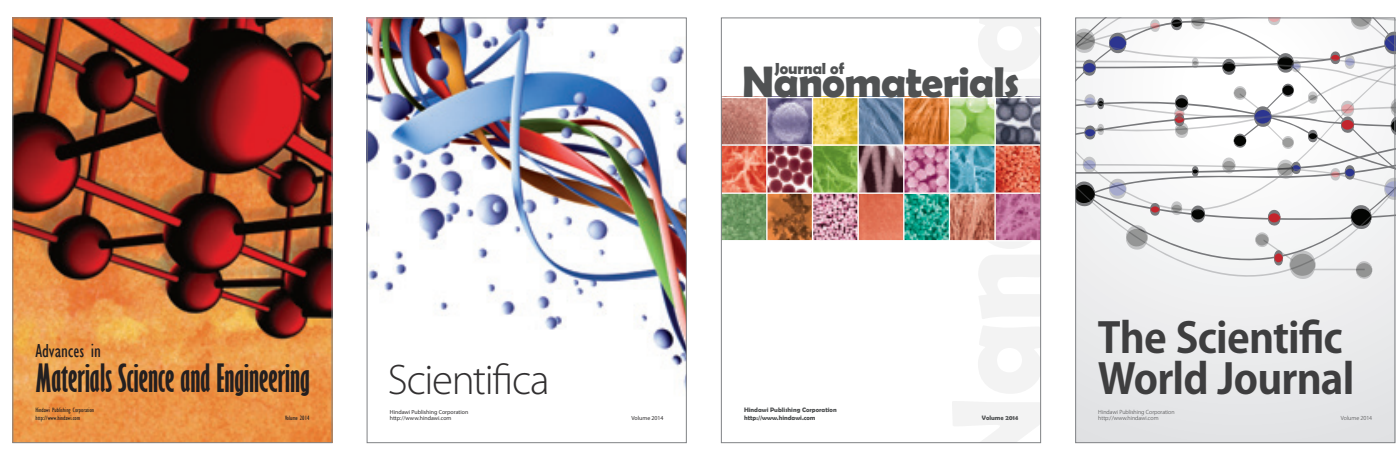

\section{The Scientific World Journal}
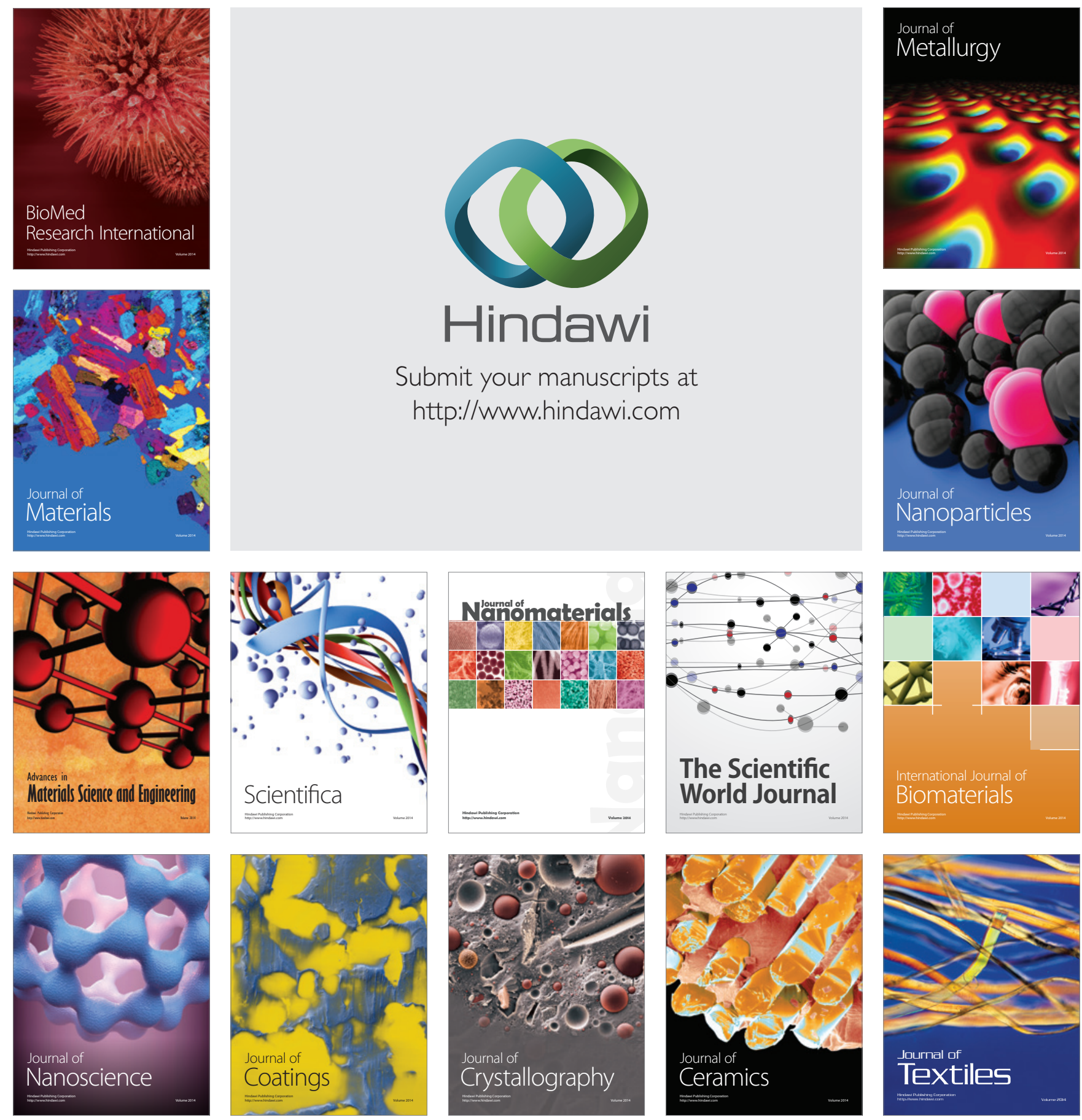